\title{
THE INFLUENCE OF DISTANCE BETWEEN ELECTRODES USED IN ANODIZING PROCESS ON THE PROPERTIES OF ALUMINUM OXIDE COATINGS
}

\author{
Marek BARA, Sławomir KULIG, Joanna KORZEKWA \\ University of Silesia in Katowice, Katowice, Poland, EU \\ marek.bara@us.edu.pl, sawekkulig@gmail.com, joanna.korzekwa@us.edu.pl
}

https://doi.org/10.37904/metal.2019.904

\begin{abstract}
This study developed how the changing of distance between electrodes in the anodizing process affects the surface morphology and mechanical properties of oxide coatings. Oxide coatings were prepared on aluminum alloy samples. The samples surfaces were subjected to hard anodizing process in a multicomponent electrolyte based on sulphuric acid with an addition of organic acids. Anodizing was carried out with a constant electric charge density and constant electrolyte temperature. The distances between the electrodes for subsequent samples increased. The pictures of the oxide coatings surfaces were collected by scanning microscope. The ImageJ software was used to analyze the nanomorphology of the coatings. The thickness and microhardness of the oxide coatings was determined by contact and Vickers method respectively. The geometrical structure of the surfaces of oxide coatings was determined by contact profilograph. Based on the conducted tests, it can be concluded that changing of parameters during the anodizing process influence on the surface morphology and microhardness of the oxide layers. The tests have shown that with the changing of the distance between the electrodes, the nanoporosity has changed.
\end{abstract}

Keywords: Aluminum oxide coatings, anodizing process, nanomorphology

\section{INTRODUCTION}

Oxide coatings produced on aluminum alloys are characterized by good mechanical properties and good adhesion to the substrate. They provide high hardness and good tribological properties in sliding associations with polymers [1]. Due to these features, the $\mathrm{Al}_{2} \mathrm{O}_{3}$ coatings have found applications in many branches of the machine industry. The hard oxide coating, through its characteristic fibrous microstructure and porous surface [2], is also a good matrix for composite layers [3]. The properties of oxide coatings obtained by electrochemical method depend mainly on the parameters of the anodizing process. The main parameters of the process include: current density, electrolyte temperature and time of process, although the type of electrolyte and the type of alloy that is subjected to anodization are also important to note [4,5]. The anodizing of aluminum elements is mainly used for technical purposes, e.g. in the engineering industry (cylinders of pneumatic actuators and compressors, gears), automotive (shock absorbers cylinders, engine pistons). The variety of shapes and dimensions of the anodized elements often requires to use the different electrode shapes and different distances between the electrodes in the anodizing process. The question which arises is whether the distance between the electrodes affects the surface morphology of $\mathrm{Al}_{2} \mathrm{O}_{3}$ coatings, and hence their mechanical properties? Michalska-Domańska at al investigated the influence of the distance between electrodes (up to $0.06 \mathrm{~m}$ ) on the surface morphology of $\mathrm{Al}_{2} \mathrm{O}_{3}$ coatings in constant voltage anodization [6]. These tests show that the distance between the electrodes does not significantly affect the pore size, but only on the coefficient of regularity of the porous pattern. The purpose of the present research is to check how the distance change between the electrodes (above $0.125 \mathrm{~m}$ ) affects the surface morphology and mechanical properties of oxide coatings in the DC anode process. 


\section{MATERIALS AND METHODS}

\subsection{Research Material}

The oxide coatins were obtained on $5 \times 10^{-4} \mathrm{~m}^{2}$ surface of EN AW-5251 aluminum alloy samples. Sample surfaces before anodizing were etched in $5 \% \mathrm{KOH}$ solution and then in $10 \% \mathrm{HNO}_{3}$ solution. The etching treatments were ended with rinsing in distilled water. The prepared surfaces were subjected to the process of anodic oxidation in the electrolyte, which was an aqueous solution of phthalic, sulfuric and oxalic acids. Anodizing was carried out using the constant current method by stabilized GPR-25H30D power supply. The anodizing process was carried out at a constant time of $1 \mathrm{~h}$, at a current density of $3 \mathrm{~A} / \mathrm{dm}^{2}$ and a bath temperature of $296 \mathrm{~K}$. The spacings between electrodes for subsequent samples increased by $0.125 \mathrm{~m}$, from $0.125 \mathrm{~m}$ to $1 \mathrm{~m}$. After anodizing the samples with the $\mathrm{Al}_{2} \mathrm{O}_{3}$ layer were rinsed in distilled water.

\subsection{Research Methodology}

The morphology studies of the surface layers were carried out using a JEOL JSM-7100F scanning microscope at 2000x and 50000x magnification. The ImageJ 1.50i software was used for computer images analysis. The values of surface stereological parameters were calculated using appropriate computer image analysis procedures. The calculations determined the porosity, the number of nanopores and the size of the nanopores. The thickness of obtained oxide layers was measured by Dualscope MP40 thickness meter. Ten measurements were made on the length of each sample and the average values were calculated. In the crosssections scraps of the samples, Vickers indentation imprint were made with a Haneman microhardness meter, with a load of $0.3 \mathrm{~N}$ in 7 series of 3 imprints along the oxide thickness. Microhardness was determined from microscope photographs taken by the microscope Neophot 2 at 1000x magnification. To determine the surface roughness of the layers, surface geometric structure tests were performed using a Form Talysurf Series 2, 3D profiler. The tests were conducted using a systematic scanning method.

\section{RESULTS AND DISCUSSION}

Morphology images of oxide coatings, made at 2000x magnification, show characteristic aluminum oxides surface porosity. Macro and micropores (Figure 1a) are formed as a result of the transfer of substrate defects to the surface of the oxide coating [7]. Nanopores with a cylindrical structure visible at a magnification of 50000x (Figure 1b), are the effect of the columnar structure of the oxide [8].
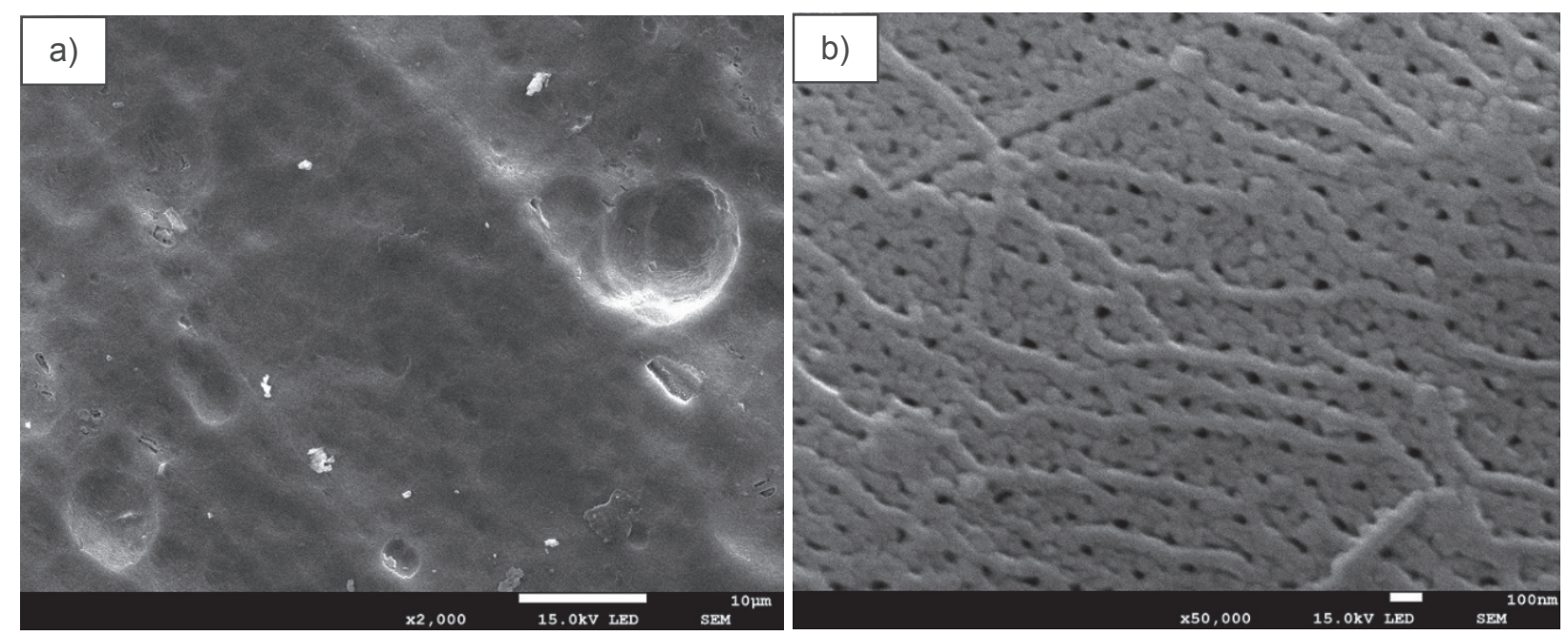

Figure 1 Image of the surface morphology of the oxide coating B (distance between electrodes $0.25 \mathrm{~m}$ ), magnification: $2000 x$ a), $50000 x$ b) 
Computer image analysis was carried out from SEM images (over 50000x). The analysis of the image was preceded by operations: Smooth, brightening (Bandpass Filter), contrasting, thresholding and binarization of the studied images. The next stages are shown in Figure 2.
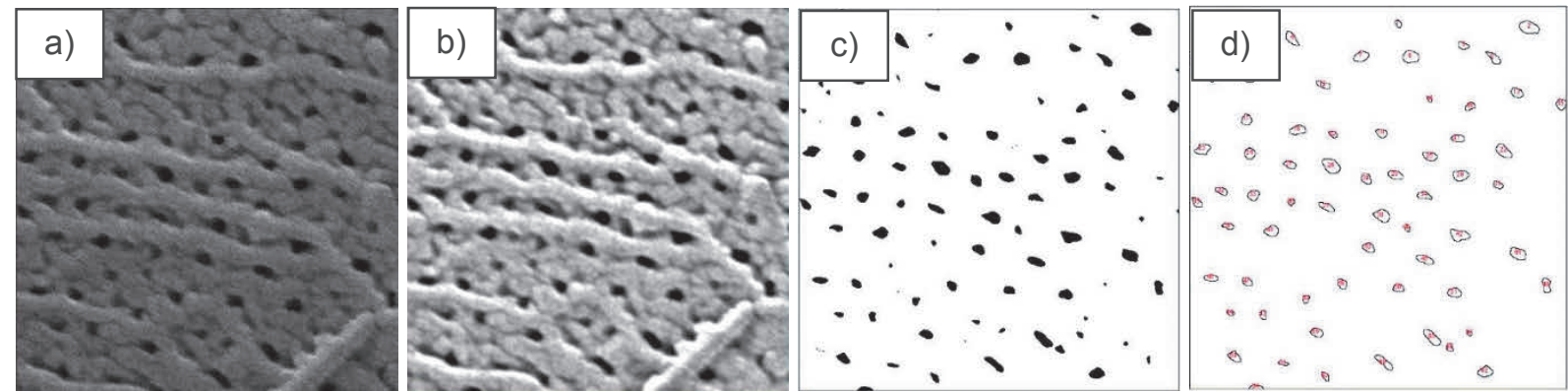

Figure 2 Stages of computer image analysis of the B coatings (distance between electrodes $0.25 \mathrm{~m}$ ): contour smoothing a), brightening and contrasting b), binarization c) analysis of objects d)

The binary image of SEM pictures of the tested coatings contained a large amount of noise. In order to avoid the influence of noise on the test results, the analysis has taken into consideration objects whose surface area was greater than $100 \mathrm{~nm}^{2}$. Image filtered in this way contained objects that represented the nanopores which were present on the surface of the coatings. The measurement results are shown in Table 1.

Table 1 Stereological parameter values from computer image analysis

\begin{tabular}{|c|c|c|c|c|c|c|c|c|}
\hline $\begin{array}{c}\text { Sample (distance of } \\
\text { electrodes) }\end{array}$ & $\begin{array}{c}\mathrm{A} \\
(0.125 \mathrm{~m})\end{array}$ & $\begin{array}{c}\mathrm{B} \\
(0.25 \mathrm{~m})\end{array}$ & $\begin{array}{c}\mathrm{C} \\
(0.375 \mathrm{~m})\end{array}$ & $\begin{array}{c}\mathrm{D} \\
(0.5 \mathrm{~m})\end{array}$ & $\begin{array}{c}\mathrm{E} \\
(0.625 \mathrm{~m})\end{array}$ & $\begin{array}{c}\mathrm{F} \\
(0.75 \mathrm{~m})\end{array}$ & $\begin{array}{c}\mathrm{G} \\
(0.875 \mathrm{~m})\end{array}$ & $\begin{array}{c}\mathrm{H} \\
(1 \mathrm{~m})\end{array}$ \\
\hline Number of pores & 287 & 339 & 287 & 236 & 272 & 222 & 271 & 276 \\
\hline Area of pores $\left(\mathrm{nm}^{2}\right)$ & 856.8 & 574.6 & 611.9 & 834.6 & 769.1 & 763.6 & 669.3 & 1235.1 \\
\hline Deviation (\%) & 385.7 & 345.2 & 366.4 & 549.8 & 443.3 & 463.6 & 329.7 & 642.1 \\
\hline
\end{tabular}

The research showed the differences in both the porosity, the number of pores and the average area of the nanopores The obtained results indicated a low surface porosity of the coatings $4.0-8.1 \%$ (Figure 3a).

In order to compare the microhardness of coatings produced under different conditions, a trend line was determined from microhardness measurements. Afterwards the microhardness of the tested coatings was calculated for a distance of $20 \mu \mathrm{m}$ from the substrate. The tests showed that the microhardness of coatings depends on changes of the electrodes distance during technological process (Figure $\mathbf{3 b}$ ).
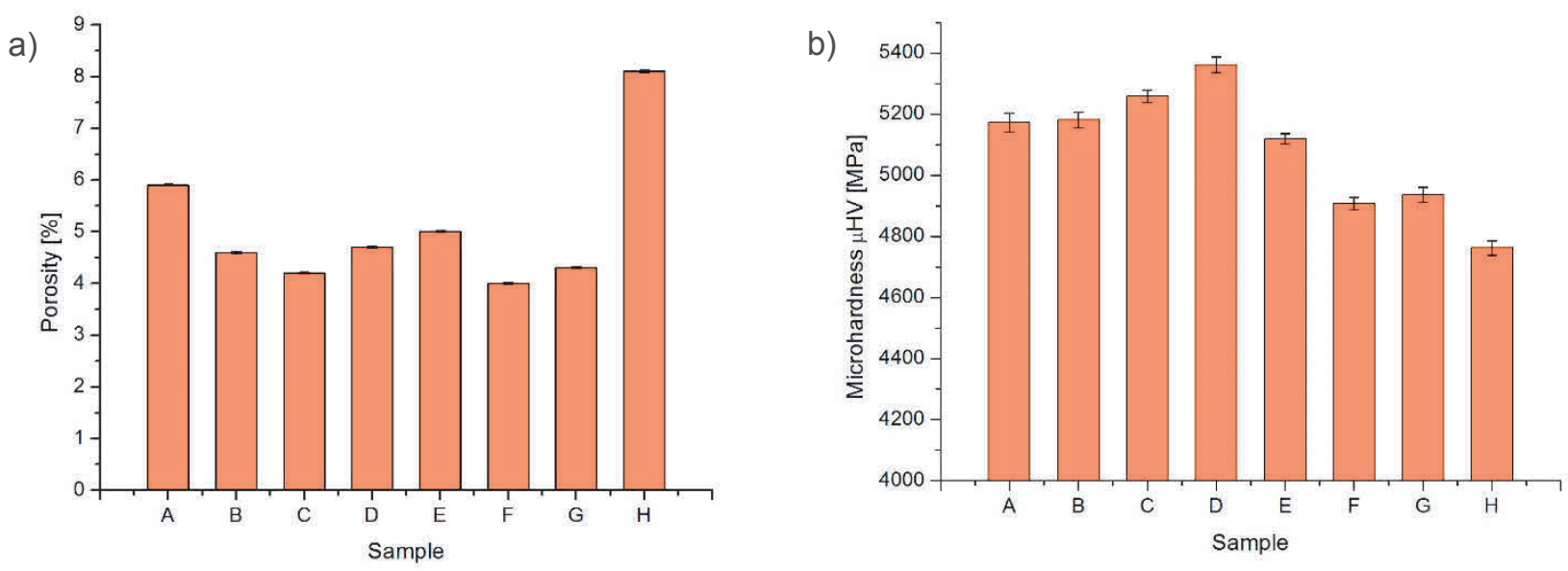

Figure 3 The influence of technological parameters on: porosity a), microhardness $b$ ) 
By analyzing the influence of technology parameters on coating properties, the relation between microhardness and the average surface area of nanopores was noticed. An increase in porosity resulted in a decreasing of microhardness of coatings.

The thickness of all coatings was about $50 \mu \mathrm{m}$. The thickness measurements of coatings did not show significant differences resulting from the use of different electrode distances (Table 2).

Table 2 List of oxide layer thicknesses

\begin{tabular}{|c|c|c|c|c|c|c|c|c|}
\hline $\begin{array}{c}\text { Sample (distance } \\
\text { of electrodes) }\end{array}$ & $\begin{array}{c}\mathrm{A} \\
(0.125 \mathrm{~m})\end{array}$ & $\begin{array}{c}\mathrm{B} \\
(0.25 \mathrm{~m})\end{array}$ & $\begin{array}{c}\mathrm{C} \\
(0.375 \mathrm{~m})\end{array}$ & $\begin{array}{c}\mathrm{D} \\
(0.5 \mathrm{~m})\end{array}$ & $\begin{array}{c}\mathrm{E} \\
(0.625 \mathrm{~m})\end{array}$ & $\begin{array}{c}\mathrm{F} \\
(0.75 \mathrm{~m})\end{array}$ & $\begin{array}{c}\mathrm{G} \\
(0.875 \mathrm{~m})\end{array}$ & $\begin{array}{c}\mathrm{H} \\
(1 \mathrm{~m})\end{array}$ \\
\hline Thickness $(\boldsymbol{\mu m})$ & 51.7 & 50.1 & 50.1 & 50.2 & 50.9 & 51.3 & 49.6 & 51.7 \\
\hline Deviation $(\boldsymbol{\mu m})$ & 0.8 & 1.7 & 1.2 & 1.1 & 0.9 & 1.1 & 0.9 & 1.5 \\
\hline
\end{tabular}

Studies of the geometric structure of the surface of the oxide coatings were carried out in order to determine their roughness. That feature significantly influences on the progress of tribological phenomena in friction nodes, where oxide coatings are used. Stereometric tests were carried out for all coating surfaces in 3D view. Isometric images of the surface of coatings are shown in Figure 4.

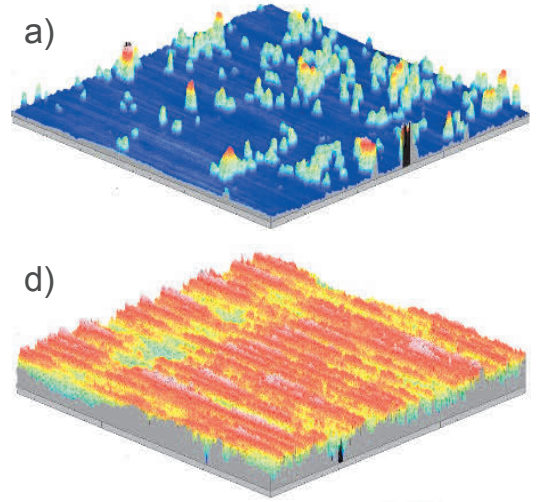

g)

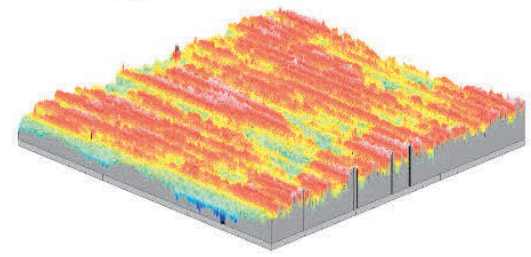

b)

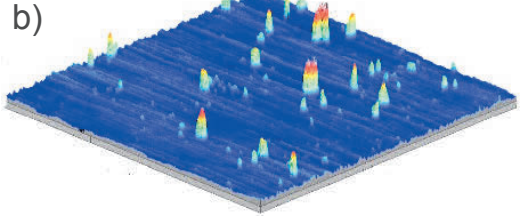

e)

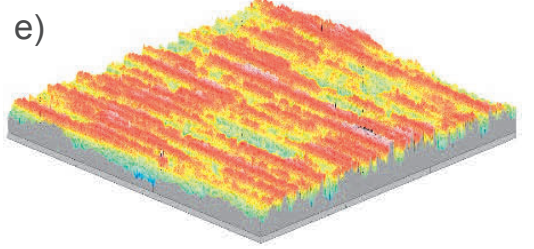

c)

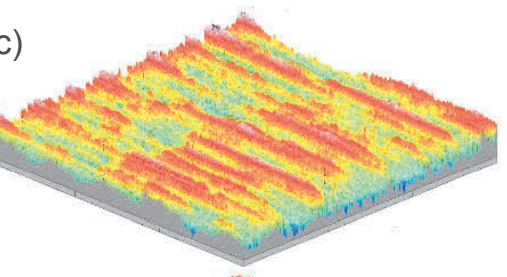

f)

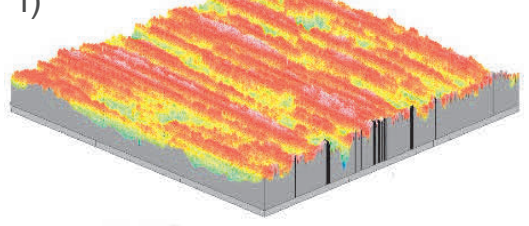

h)

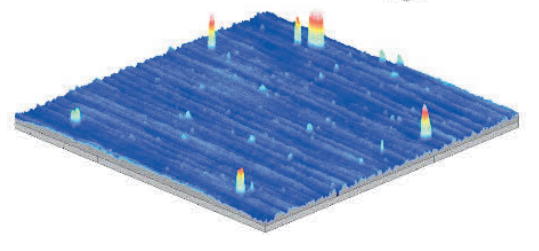

Figure 4 The influence of technological parameters on the coating's roughness: sample A a), sample B b), sample C c), sample D d), sample E e), sample F f), sample G g), sample H h)

In Table 3 presents selected amplitude parameters of all surfaces.

Table 3 Roughness parameters of oxide coatings

\begin{tabular}{|c|c|c|c|c|c|c|c|c|}
\hline $\begin{array}{c}\text { Sample (distance } \\
\text { of electrodes) }\end{array}$ & $\begin{array}{c}\mathrm{A} \\
(0.125 \mathrm{~m})\end{array}$ & $\begin{array}{c}\mathrm{B} \\
(0.25 \mathrm{~m})\end{array}$ & $\begin{array}{c}\mathrm{C} \\
(0.375 \mathrm{~m})\end{array}$ & $\begin{array}{c}\mathrm{D} \\
(0.5 \mathrm{~m})\end{array}$ & $\begin{array}{c}\mathrm{E} \\
(0.625 \mathrm{~m})\end{array}$ & $\begin{array}{c}\mathrm{F} \\
(0.75 \mathrm{~m})\end{array}$ & $\begin{array}{c}\mathrm{G} \\
(0.875 \mathrm{~m})\end{array}$ & $\begin{array}{c}\mathrm{H} \\
(1 \mathrm{~m})\end{array}$ \\
\hline $\mathrm{Sq}(\boldsymbol{\mu \mathrm { m }})$ & 1.298 & 0.480 & 0367 & 0.350 & 0.352 & 0.392 & 0.341 & 0.478 \\
\hline Sz $(\boldsymbol{\mu m})$ & 13.584 & 8.768 & 2.336 & 2.304 & 2.288 & 2.752 & 2.144 & 6.243 \\
\hline Ssk & 3.327 & 4.984 & 0.120 & -0.037 & 0.011 & -0.190 & -0.099 & 6.211 \\
\hline
\end{tabular}

The values of the mean square surface deviation $S q$ and the total height of the roughness $S z$ indicate the low surface roughness of the oxide coatings generated at the distances between the electrodes $0.375-0.875 \mathrm{~m}$. 
The layers A, B and $\mathrm{H}$ are characterized by an increased value of these parameters, due to the occurrence of single hills on their surface roughness. The Ssk asymmetry coefficient for C - $G$ samples has a value close to zero, which indicates the concentration of material near the vertices of the profile. A negative value of the asymmetry coefficient is very suitable for coatings intended for sliding associations with polymeric materials

\section{CONCLUSION}

Based on the tests and the results, it can be concluded that the change of the distance between the electrodes (in the range of $0.125-1 \mathrm{~m}$ ) affected the changes of surface morphology, microhardness and roughness of oxide coatings produced in the process of DC anode. All the obtained coatings were characterized by porosity of $4.0-8.1 \%$, which predisposed coatings for sliding cooperation with polymers under technically dry friction conditions. The highest porosity was demonstrated for coatings produced under extreme conditions, i.e. for samples $\mathrm{A}$ and $\mathrm{H}$. It was shown that the increasing in porosity resulted in a decreasing the microhardness of coatings. Stereometric analysis showed that the coatings obtained at the distance between the electrodes in the range of $0.375-0.875 \mathrm{~m}$ are most predisposed to sliding associations. Coating thickness tests showed that the change of the distance between the electrodes does not significantly change the thickness of the coatings. Changes of coating properties are most likely due to changes in the shape of the electric field and the distribution of charges in the electrolyzer during the process. The anodizing of elements with various dimensions may therefore result in obtaining the oxide coatings with different properties.

The presented approach and obtained results may be useful for other possible coatings [9-12], surface condition assessment [13] and their machining [14]. In further investigation, the results dataset will be analyzed by more complex statistical methods [15-17] and image analysis methods [18], even in fuzzy [19] or Monte Carlo approach [20], and obtained results should be included, as appropriate decision rules, into a knowledge database of a decision support system [21].

\section{REFERENCES}

[1] KMITA, T. and SKONECZNY, W. Increase of operational durability of a plastic material-oxide coating couple as a result of the application of a pulsed anodizing process. Maintenance and Reliability. 2010. vol. 45, pp. 77-82.

[2] KMITA, T., SZADE, J. and SKONECZNY, W. Gradient oxide layers with an increased carbon content on an EN AW-5251 alloy. Chemical and Process Engineering. 2008. vol. 29, pp. 375-387.

[3] KIM, K., KIM, M. and CHO, S.M. Pulsed electrodeposition of palladium nanowire arrays using AAO template. Materials Chemistry and Physics. 2006. vol. 96, pp. 278-282.

[4] JIA, Y., ZHOU, H., LUO, P., LUO, S., CHEN, J. and KUANG, Y. Preparation and characteristics of well-aligned macroporous films on aluminum by high voltage anodization in mixed acid. Surface \& Coatings Technology. 2006. vol. 201, pp. 513-518.

[5] FRATILA-APACHITEI, L.E., TICHELAAR, F.D., THOMPSON, G.E., TERRYN, H., SKELDON, P., DUSZCZYK, J. and KATGERMAN, L. A transmission electron microscopy study of hard anodic oxide layers on $\mathrm{AISi}(\mathrm{Cu})$ alloys. Electrochimica Acta. 2004. vol. 49 pp. 3169-3177.

[6] MICHALSKA-DOMAŃSKA, M., STĘPNIOWSKI, W. J. and SALERNO, M. Effect of inter-electrode separation in the fabrication of nanoporous alumina by anodization. Journal of Electroanalytical Chemistry 2018. vol. 823, pp. 47-53.

[7] BARA, M. and KUBICA, M. Influence of substrate preparation on the shaping of the topography of the surface of nanoceramic oxide layers. Applied Surface Science 2014. vol. 293, pp. 306-311.

[8] KUBICA, M., SKONECZNY, W. and BARA, M. Analysis of $\mathrm{Al}_{2} \mathrm{O}_{3}$ nanostructure using scanning microscopy. Scanning 2018, art. 8459768.

[9] KLIMECKA-TATAR, D., BORKOWSKI, S. and SYGUT, P. The kinetics of Ti-1Al-1Mn alloy thermal oxidation and charcteristic of oxide layer. Archives Metallurgy and Materials. 2015, vol. 60, pp. 735-738. 
[10] LIPINSKI, T. Double modification of AISi9Mg alloy with boron, titanium and strontium. Archives Metallurgy and Materials. 2015, vol. 60, pp. 2415-2419.

[11] KLIMECKA-TATAR, D., PAWLOWSKA, G. and RADOMSKA, K. The effect of Nd12Fe77Co5B6 powder electroless biencapsulation method on atmospheric corrosion of polymer bonded magnetic material. In METAL 2014: 23rd Int. Conf. on Metallurgy and Materials. Ostrava: TANGER, pp. 985-990.

[12] SYGUT, P., KLIMECKA-TATAR, D. and BORKOWSKI, S. Theoretical analysis of the influence of longitudinal stress changes on band dimensions during continuous rolling process. Archives Metallurgy and Materials. 2016, vol. 61, pp.183-188.

[13] ULEWICZ, R. and NOVY, F.R. The influence of the surface condition on the fatigue properties of structural steel. Journal of the Balkan Tribological Association 2016, vol. 22, pp. 1147-1155.

[14] RADEK, N., SZCZOTOK, A., GADEK-MOSZCZAK, A., DWORNICKA, R., BRONCEK, J. and PIETRASZEK, J. The impact of laser processing parameters on the properties of electro-spark deposited coatings. Archives Metallurgy and Materials. 2018, vol. 63, pp.809-816.

[15] PIETRASZEK, J. and GOROSHKO, A. The heuristic approach to the selection of experimental design, model and valid pre-processing transformation of DoE outcome. Advanced Materials Research-Switz. 2014, vol. 874, pp.145-149.

[16] SKRZYPCZAK-PIETRASZEK E., PISKA, K. and PIETRASZEK, J. Enhanced production of the pharmaceutically important polyphenolic compounds in Vitex agnus castus L. shoot cultures by precursor feeding strategy. Enginnering in Life Sciences. 2018, vol. 18, pp. 287-297.

[17] SKRZYPCZAK-PIETRASZEK, E., REISS, K., ZMUDZKI, P. and PIETRASZEK, J. Enhanced accumulation of harpagide and 8-O-acetyl-harpagide in Melittis melissophyllum L. agitated shoot cultures analyzed by UPLCMS/MS. PLOS ONE 2018, vol.13, e0202556.

[18] GADEK-MOSZCZAK, A., RADEK, N., WRONSKI, S. and TARASIUK, J. Application the 3D image analysis techniques for assessment the quality of material surface layer before and after laser treatment. Advanced Materials Research-Switz. 2014, vol. 874, pp. 133-138.

[19] PIETRASZEK, J., KOLOMYCKI, M., SZCZOTOK, A. and DWORNICKA, R., 2016. The fuzzy approach to assessment of ANOVA results. In ICCCI 2016: Conf. on Comp. Collective Intell. Springer, pp. 260-268.

[20] PIETRASZEK, J., SZCZOTOK, A., KOLOMYCKI, M., RADEK, N. and KOZIEN, E. Non-parametric assessment of the uncertainty in the analysis of the airfoil blade traces. In METAL 2017: 26th Int. Conf. Metallurgy and Materials. Ostrava: TANGER, 2018, pp. 1412-1418.

[21] PACANA, A., PASTERNAK-MALICKA, M., ZAWADA, M. and RADON-CHOLEWA, A. Decision support in the production of packaging films by cost-quality analysis. Przemysł Chemiczny 2016, vol. 95, pp. 1042-1044. 